\title{
Teachers' Misunderstanding The Concept Of Inclusive Education
}

\author{
Tomomi Sanagi, Ph.D., Chiba University, Japan
}

\begin{abstract}
Teachers' misunderstanding the concept of inclusive education will not lead to good practices, rather make an exclusive environment for pupils with special educational needs in mainstream schools. This study clarified teachers' attitudes towards the image of inclusive education with conjoint analysis and cluster analysis. The participants for this study were 182 teachers who were from both mainstream schools and special schools. Their image about inclusive education was mainly dependent upon the organization of group and size of a group. The subfile summary of the conjoint analysis indicated that the teacher's views of inclusive education as images of "expanding school environment to include a child", withdrawal to "resource room", "small groups", and "a pupil with disability in a mainstream group." On the other hand, images of "repudiation of segregated learning opportunities", "homogeneous group", "a large size group", and "various attributes in a group" were perceived as "non-inclusive." The author has divided the participants into two groups by cluster analysis. The factors in dividing were discussed as not depend on their teaching experience nor school type, but local school environment - such as enrollment ratio of foreign pupils.
\end{abstract}

Keywords: Inclusive Education; Teacher's Attitudes; Conjoint Analysis

\section{INTRODUCTION}

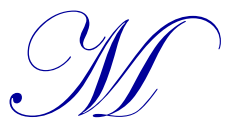

any scholars have defined inclusive education in various ways. Sanagi (2011) notes that a "process that allows expansion of the scope of inclusion so as to include diversity in individual education needs" is a shared aspect of the various definitions of inclusive education. In other words, the target for inclusion is primarily diversity, rather than children in the concept. Changing the school learning environment to include the special educational needs of children can be expressed as a process by which the "special" provision that has become effective are transformed into "regular" provisions. This very process corresponds with the concept of inclusive education. As a result, children having particular educational needs can be included in a certain school. From a phenomenological perspective, we are able to regard it as an inclusion superficially. However, it is appropriate to understand that the positioning of learning opportunities for such children is established through the process of including their educational needs.

However, some people seem to jump too quickly to the conclusion that inclusive education means education at mainstream schools. For them, it is easier to understand a situation in which children who have learned at special schools or special units than mainstream schools participate in learning activities in mainstream schools than to achieve a more structural understanding of the concept. For the development of inclusive education in various countries, it is essential to exchange opinions and hold discussions from different viewpoints. However, if such development progresses with an ambiguous shared understanding of a basic concept, the condition pointed out by Terzi (2010) will take place. That is, although overall consensus has been reached concerning the value of 'inclusion,' none of the opinions correspond to specific measures to be taken in the context of education. (Terzi, 2010)

Regarding the promotion of inclusive education, Ainscow (1999) indicated that the definition of inclusive education was understood in a confused manner, or not understood at all, by local education authorities in the U.K. In Japan, the views of inclusion between the Cabinet Office and Ministry of Education, Culture, Sports, Science and Technology (MEXT) do not currently match (Watanabe, 2012). It is the condition that Terzi (2010) describes. Furthermore, various forms of campaigns and the stakeholders involved with integrated education have shown that the concept of inclusive education still tends to be used to serve their own interests. 
Under the concept of inclusive education, separated learning opportunities at special schools and so forth have been affirmed as social resources internationally, such as by the United Nations Educational, Scientific, and Cultural Organization (UNESCO, 1994). However, influenced by the perspectives that seek to repudiate separated learning opportunities in Japan, some literature still asserts that the repudiation of separated learning opportunities constitutes the philosophy of inclusive education. Previous studies that reviewed teachers' attitudes towards inclusive education have dealt with subject matter similar to that of this study. However, even in such studies, there have been misunderstandings. For example, it has been stated that the term 'inclusive education' refers to a concept in which all school students belong to only mainstream schools and educational provisions are to be made on an individual oriented (Ueno and Nakamura, 2011).

There should be no objection to proactively accepting various opinions from different standpoints concerning the development of inclusive education (Benjamin, 2002). On the other hand, if the same term is defined by different concepts in discussions, effective practice development will be hindered. How teachers understand the concept of inclusive education directly affects practices and development. Thus, it is quite important to urge teachers to have an appropriate conceptual understanding.

The Japanese government has ratified the Convention on the Rights of Persons with Disabilities, and it is thus expected that the term "inclusive education" will be used as an official term sooner or later within the Japanese education system. An urgent task is to guide all teachers involved with practical applications having at least an appropriate conceptual understanding and accurate knowledge.

The purpose of this study is to obtain the necessary data for solving the aforementioned problem, understand the image of inclusive education held by teachers, and clarify its characteristics.

\section{METHOD}

\section{Subject}

The participants were 200 teachers working in primary schools, junior high schools, high schools, and special schools.

In cases wherein the participants had never heard the term "inclusive education," the reliability of the answers was remarkably low. Thus, only participants who had had a certain interest in "special support education" (the name "special support education" is the correct expression of special needs education in Japan) and had already heard of the term inclusive education were targeted for the analysis. 184 teachers have answered. In the conjoint analysis method, if the answers are even partially defective, no processing will take place. Additionally, in the full conceptual method, if the same rating applies to all items, no processing will take place, either. The final number of teachers analyzed was 182 , as two teachers were excluded by the incomplete questionnaire. The response rate was $91.0 \%$. The period for the survey was from January 2012 to August 2012.

\section{Survey}

The questionnaires consisted of items for a conjoint analysis (full concept method), which were represented by a diagram relating to respondent attributes and an image relating to inclusive education. The questionnaires for the conjoint analysis comprised a combination of four factors as using pictures: (1) inclusivity image (put a pupil into a mainstream classroom -- expanding environment to include a pupil); (2) images on learning group organization (repudiation of separated learning opportunities -- a homogeneous group setting -- resource room system); (3) images on size of learning group (a large group -- small groups -- individualized lesson); and (4) images of diversity of attributes (a pupil with disability in a group -- various attributes in a group).

Specifically, nine patterns were extracted using an orthogonal layout based on the combination " 2 × 3 × 3 × $2=36$," which is the level of all factors. The SPSS Conjoint Option (ver. 20) was used for the extraction. The questionnaires for the conjoint analysis with 11 items, to which two items (i.e., holdouts card) had been added to analyze reliability. 
The questionnaires used in the study contained items that reflected the accuracy of knowledge ("repudiation of separated learning opportunities" about the "learning group organization" factor and "diversity of attributes"). Most of the items inquired about several types of learning group organization and the sizes of learning groups concerning inclusive education, rather than questioning the participants' knowledge. The ingenuity described above allowed the avoidance of the tendency to answer dishonestly based on bias, whereby the respondents would suspect that the accuracy of their knowledge might be questioned. All levels were presented using combinations of images with words so that the respondents were easily able to react as intuitive as possible to the evaluation items.

\section{RESULTS}

\section{Characteristics of Subfile Summary for All Respondents}

A subfile summary concerning the average relative importance for all respondents is presented in Figure 1.

For the conjoint analysis method, the importance of the factors is represented by relative relationships. That is to say, the values of the factors are represented by percentage values, with the assumption that the total is 100 .

As seen in Figure 1, it is understood that the respondents evaluated their own images of inclusive education based on two factors (which occupy relative importance, accounting for two-thirds of the entirety): learning group organization and size of the learning group.

Figure 1. Average relative importance (summary)

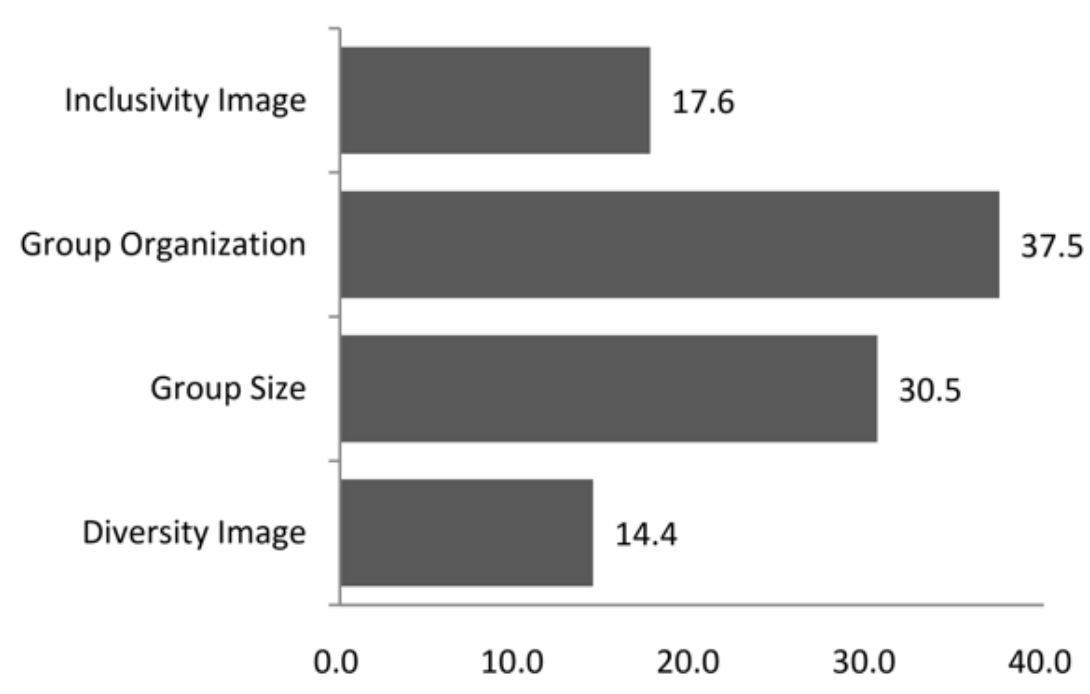

Overall, the following ratings represented provisions indicating an image of inclusive education that was closer to reality: "expanding environment to include a pupil", "resource room system", "individualized lesson", "small groups", and "a pupil with disability in a group." (upward direction bar in Figure 2) On the other hand, the following ratings represented provisions indicating an image of inclusive education that was NOT close to reality: "put a pupil into a mainstream classroom", "repudiation of separated learning opportunities", "homogenous groups", "a large group", and "groups of children with various attributes."(downward direction bar in Figure 2) Regarding "inclusivity" factor, the image "expanding environment to include a pupil" accurately reflects the fact that the concept of inclusive education is based on processes. This image represents the overall tendency, and can be accepted as being appropriate for the future understanding of the concept. "Resource room system" was rated as close to the reality of inclusive education. This rating rose from two possibilities: (1) teachers evoked enrollment in normal classes based on resource room system and (2) ancillary lessons added as needed was evoked to embrace the diversity of individual educational needs. 
Figure 2. Utility Scores (all participants)

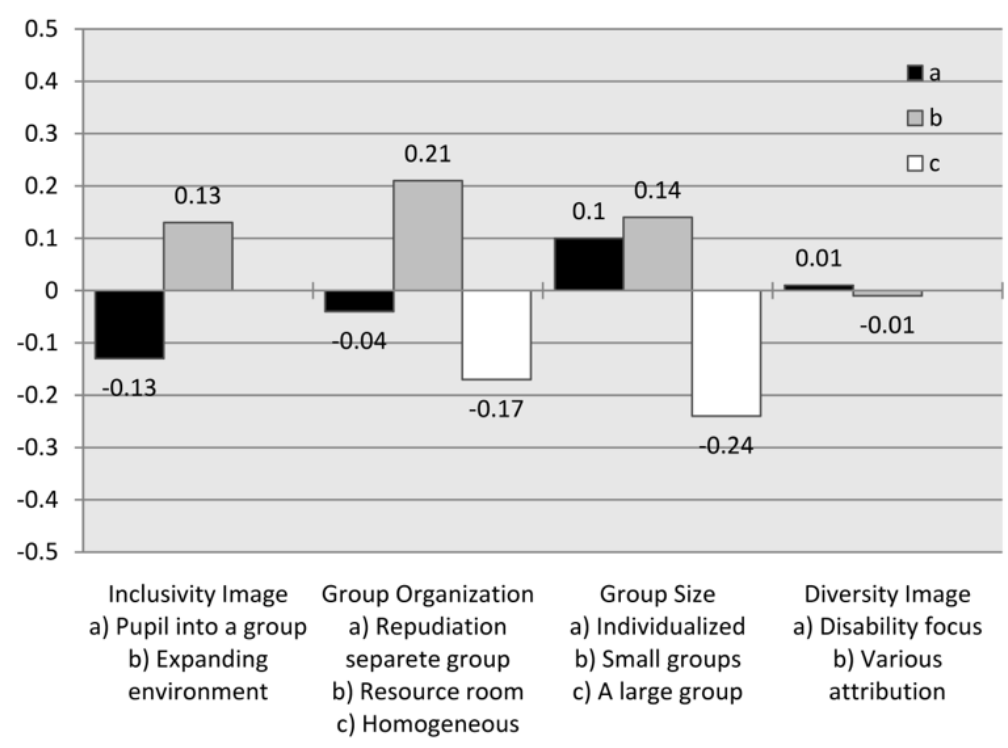

The characteristics of the subfile summary or the average relative importance of all respondents are that the inclusive education image was rated as closer to the reality of study groups for individuals or small study groups, and far from the reality of a large study groups. It is possible for those teachers to consider the provision of teaching for pupils as inclusive education. "Special support education" just targets children with disabilities now and as a result, the teachers' image of inclusive education exclusively tends to involve children with disability.

\section{Classification by Cluster Analysis and Group Characteristics}

The respondents were classified via cluster analysis based on the utility scores of each level. It was determined that it would be appropriate to roughly divide the subjects into two categories based on sample size and dendrogram characteristics. Cluster 1 had 87 people and cluster 2 had 95 people.

\section{Characteristics of Cluster 1 (Figure 3)}

Figure 3. Average relative importance (Cluster 1 teachers)

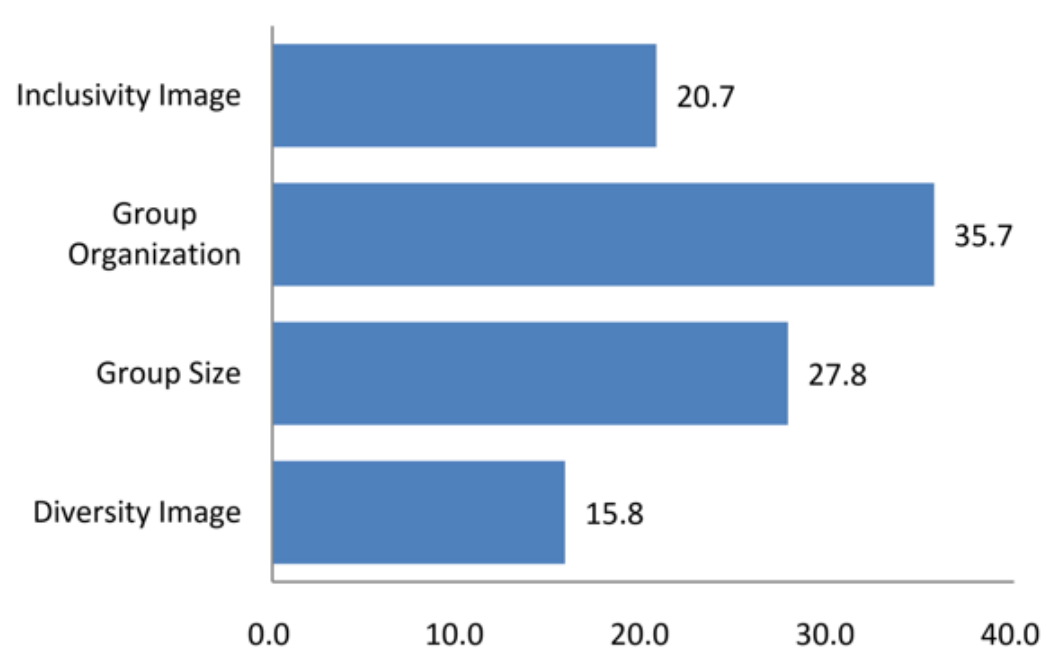


Figure 4. Utility Scores (Cluster 1)

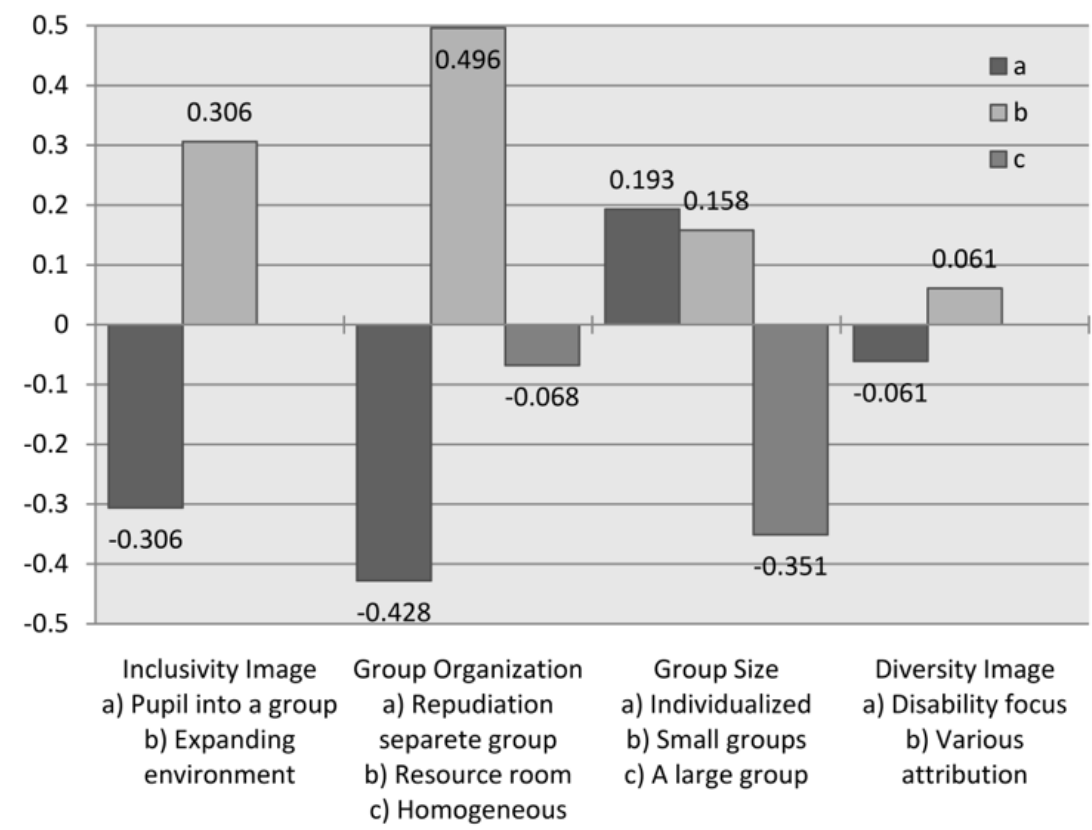

The answers of the people in this group were characterized by the following elements concerning the image of inclusive education (in detail Figure 4): "expanding environment to include a pupil", "repudiation of separated learning opportunities", "denying resource room", affirmation of "individualized lesson" and "small groups", repudiation of "a large group", and "various attribute in a group.

The cluster 1 respondents clarified that "repudiation of separated learning opportunities" differed from the reality of inclusive education. This reflects that they have an accurate understanding of inclusive education.

The conjoint analysis method is for the relative assessment of factors and factor levels, and clarification as to what conditions should be focused. Thus, the larger the absolute value for a given level was, the more the respondents focused on such level when they made relevant judgments. It was clear that a strong repudiation of "repudiation of separated learning opportunities" (i.e., the affirmation of separated educational opportunities) was their judgment criterion. In this survey, the levels and factors relating to the diversity of attributes were established as information that reflected the respondents' knowledge of inclusive education. Cluster 1 respondents were found to have an image that entailed accurate knowledge.

They believed that the resource room system strongly described inclusive education. At the same time, they rated large classes as not being part of the image of inclusive education. Also, the respondents selected "expanding environment to include a pupil" as corresponding to the reality of inclusive education. It was speculated that they considered inclusivity an aspect of inclusive education instead of integrated education. The results indicated that the average relative importance of this factor was 20.7 (Figure 3), which represented a weight of appropriately one-fifth of the total.

As regards a factor on the diversity of attributes, the current Japanese special support education system targets only pupils with a disability. Thus, it was expected that the respondents would have an image of children with a disability when issues in inclusive education were discussed.

However, cluster 1 respondents saw inclusive education as involving "various attributes in a group." The utility scores range for the factor levels of such factors was so narrow that there was no major influence on the evaluation of the nature of inclusive education. As in cases in which the respondents in cluster 1 evaluated "repudiation of separated learning opportunities" as not reflecting inclusive education, it was suggested that the image they formed was based on more accurate knowledge about inclusive education. 


\section{Characteristics of Cluster 2 (Figure 5)}

The answers of the participants in this group concerning their images of inclusive education were characterized by the following elements (in detail Figure 6): "put a pupil into a mainstream classroom", "repudiation of separated learning opportunities", repudiation of "homogeneous groups", affirmation of "small groups", repudiation of "a large group", and "a pupil with disability in a group (disability focused)."

Figure 5. Average relative importance (Cluster 2 teachers)

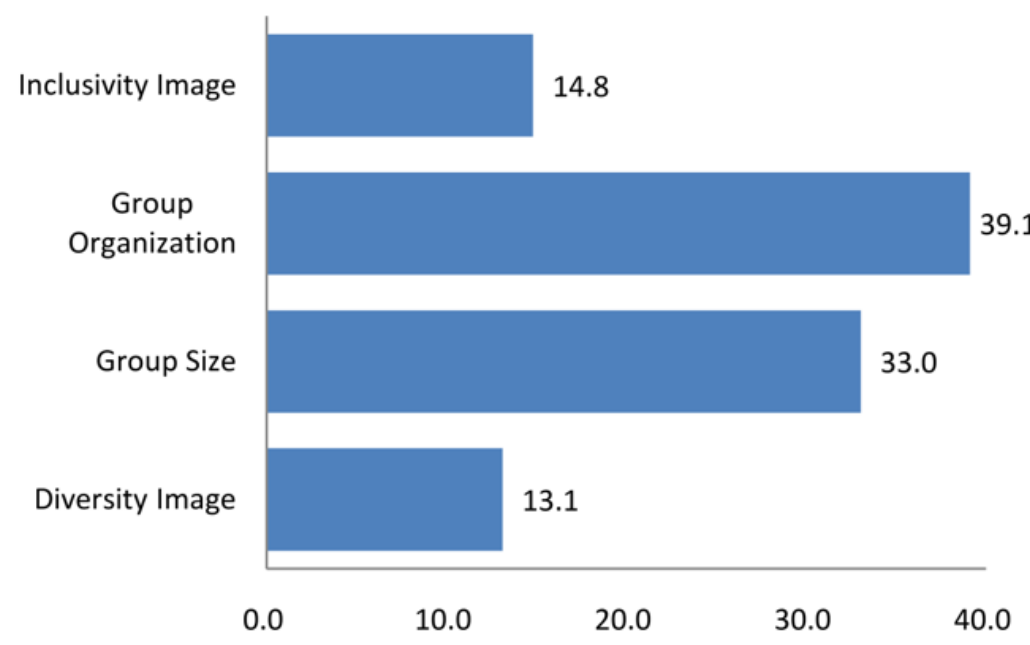

Figure 6. Utility Scores (Cluster 2)

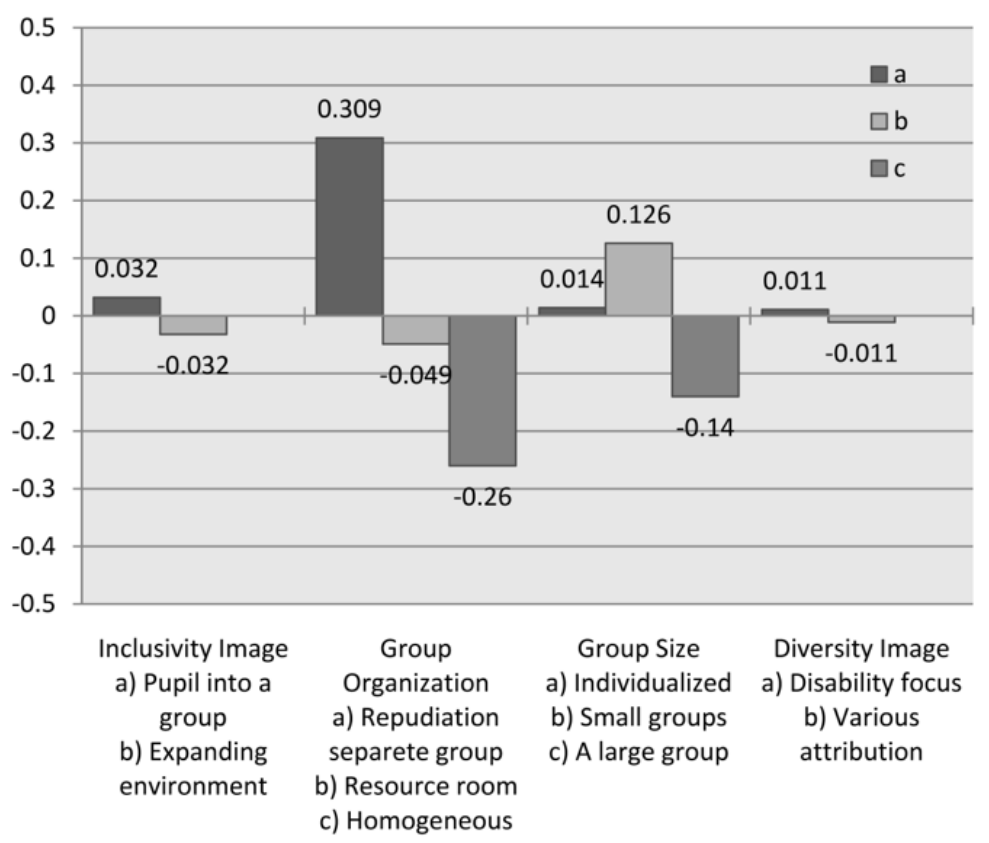

The cluster 2 respondents considered inclusive education to be characterized by the "repudiation of separated learning opportunities" and repudiation of forming a "homogeneous group" as separate learning groups comprising pupils with disability and other pupils with each. These criteria relate to knowledge about inclusive education; it was 
discovered that the cluster 2 respondents did not have accurate knowledge of inclusive education. The average relative importance concerning factor on learning group organization, including those point, extended to about $40 \%$ (Figure 5). Thus, cluster 2 respondents depended heavily on such factors in their overall image of inclusive education.

Moreover, this group was characterized by the following points. The cluster 2 respondents rated "small groups" as being closer to the reality of inclusive education. At the same time, "individualized lesson" did not necessarily correspond to the concept of inclusive education. The cluster 2 respondents rated separated learning as not being a suitable image on inclusive education. In light of this point, they might reach the conclusion above because they had regarded "individualized lesson" as separation.

The range of utility scores (Figure 6) was narrow for factors relating to factor on "inclusivity" and, as a result, the relative importance was low (14.8\% in Fig 5). It was found that the cluster 2 respondents hardly considered "inclusivity" when evaluating the image of inclusive education. However, they considered an image of "put a pupil into a group" to be an aspect of inclusive education.

In the same fashion, the relative importance given to factor on the diversity of attributes was low in Figure 5 . The cluster 2 respondents give very little consideration to "diversity of attributes" when evaluating inclusive education. Their view was limited to children with disability. Provisions concerning this factor reflect whether or not the respondents have an accurate knowledge of inclusive education. Thus, it was clarified that the respondents in this cluster did not have accurate knowledge of this factor, as in the case of "repudiation of separated learning opportunities." They held on to this perspective even if the resource room system was different from the image of inclusive education. This notion revealed that cluster 2 respondents' image of inclusive education involved small learning groups, including pupils with a disability, which was opposite to that of "separated education."

\section{Comparison between Clusters 1 and 2}

A comparison between clusters 1 and 2 is shown in Figures 7 to 10, according to the order of factors.

A major difference was found in the utility scores on "inclusivity" image for both clusters, as shown in Fig. 7. In cluster 1 teacher, this factor had a relatively large influence on the evaluation of inclusive education. However, in cluster 2, it hardly had any influence. "Expanding environment to include a pupil" was evaluated in cluster 1 as reflecting the image of inclusive education. On the other hand, in cluster 2, the image of integrated education was based on "put a pupil into a mainstream classroom."

Figure 7. Inclusivity Image

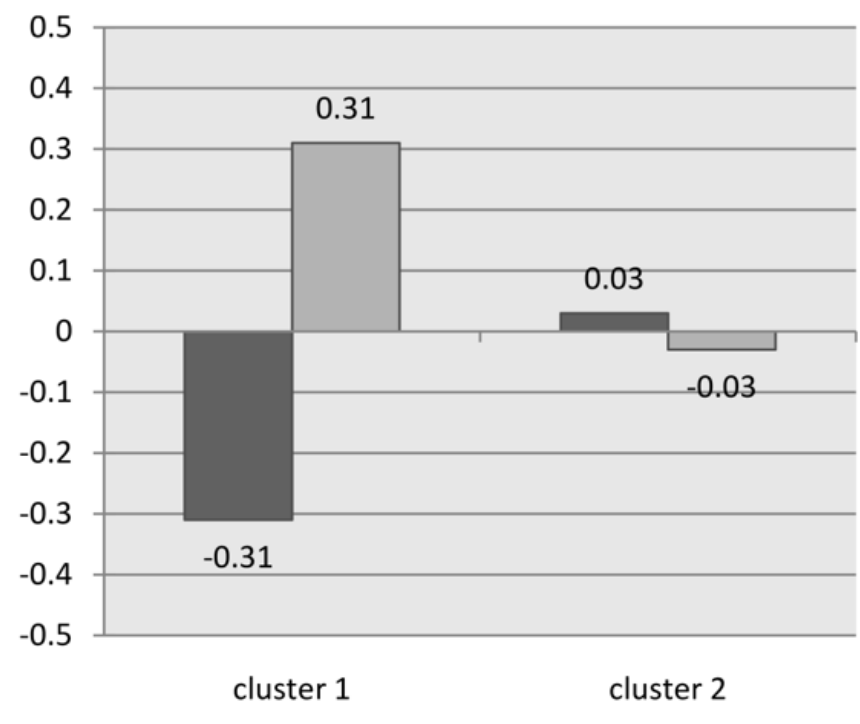

put a pupil into a mainstream classroom $\square$ expanding environment includes a pupil 
The difference in conception between the two clusters is also clearly indicated in Figure 8 on the image of group organization as inclusion. In cluster 1, the respondents made an image assessment based on accurate knowledge that separated learning opportunity would not be repudiated in inclusive education. Cluster 2 rated "repudiation of separated learning opportunities" as corresponding to the image of inclusive education.

Figure 8. Group Organization

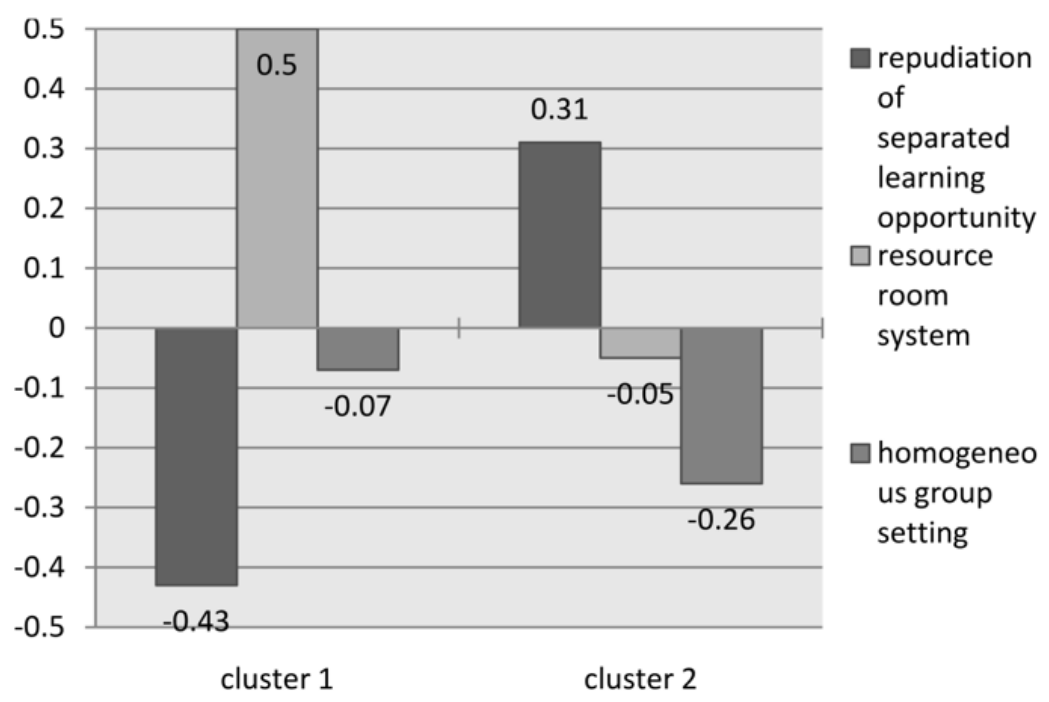

The respondents of clusters 1 and 2 rated "a large group" as being farther from the image of inclusive education, as shown in Figure 9. This tendency was particularly strong in cluster 1, whose respondents rated "individualized lesson" and the size of a "small groups" as being closer to the image of inclusive education. Meanwhile, cluster 2 respondents rated "individualized lesson" as having nothing to do with the image of inclusive education. Although inclusive education contains diversified attributes, neither cluster was highly aware that "diversity of attributes" was a factor characterizing inclusive education (Figure 10). Thus, it could be concluded that the respondents of cluster 1 appropriately understood the concept. However, it was clear that the viewpoint of inclusion of diversified attributes as a substantial element of inclusive education was not widespread enough.

Figure 9. Group Size

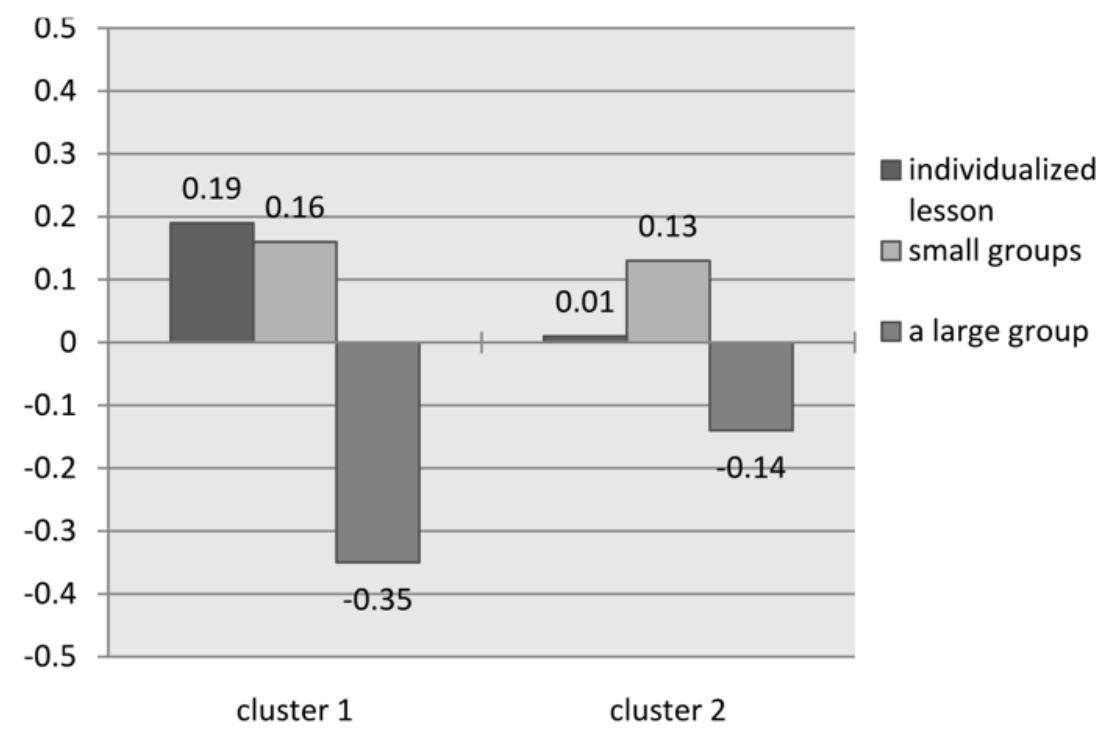


Figure 10. Diversity Image

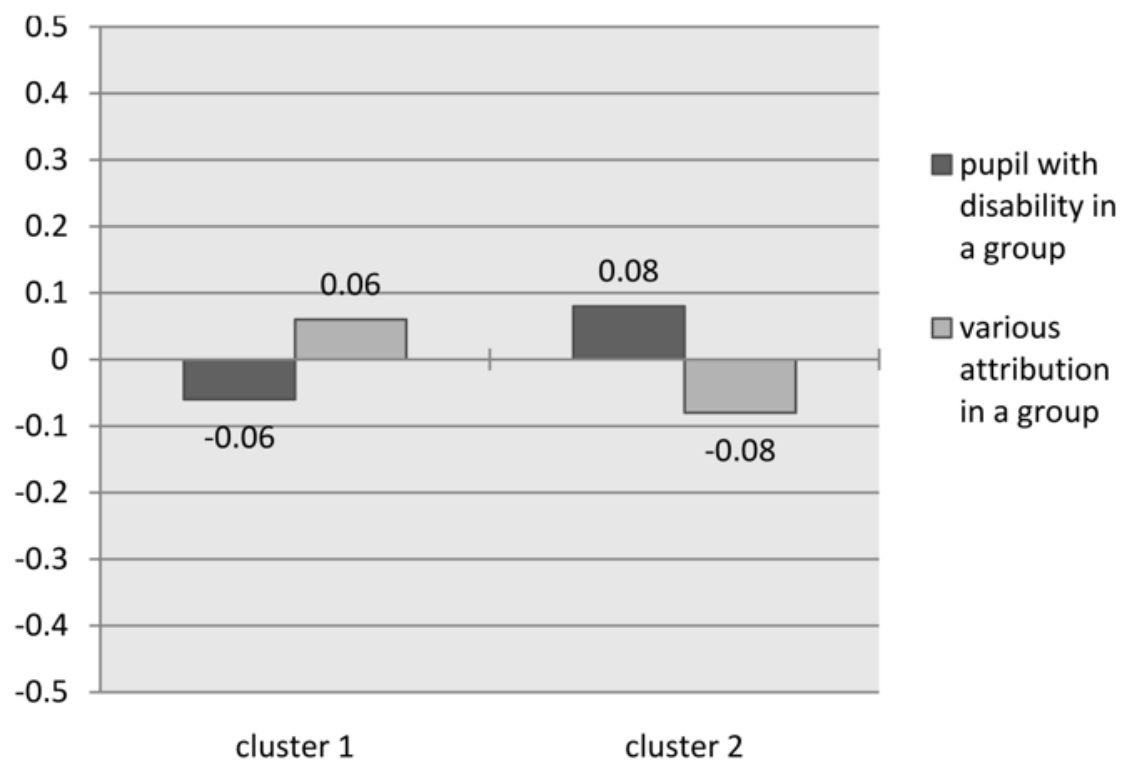

\section{Relationship between Classification by Cluster Analysis and the Locations of the Schools to which the Groups Belong (Table 1)}

As described above, the respondents were roughly divided into two categories. How different were attributes of the teachers that comprise the clusters?

The distribution of the types of schools (primary, secondary, or special) where the teachers worked was reviewed, and no difference between the two clusters was discovered. Additionally, there was no difference in the participants' age or number of years of teaching experience. The results indicated that as regards their images of inclusive education, the participants of this study were not influenced by the types of schools in which they were working, their age, or the number of years of teaching experience.

The areas where the schools of the participants located were then organized based on the unit of local education authority. The results are presented in Table 1 .

Table 1. Clusters and Education Authority

\begin{tabular}{l|c|c|c|c|c|c|c}
\hline \multicolumn{1}{c}{ Education Authority } & City C & M & HK & T & HS & K & Total \\
\hline Cluster 1 teachers & 8 & 9 & 13 & 25 & 17 & 15 & 87 \\
\hline Cluster 2 teachers & 16 & 16 & 18 & 23 & 16 & 6 & 95 \\
\hline school rate which has foreign pupils & $72 \%$ & $47 \%$ & $48 \%$ & $72 \%$ & $62 \%$ & $81 \%$ & - \\
\hline cluster 1 / cluster 2 & 0.50 & 0.56 & 0.72 & 1.09 & 1.06 & 2.50 & - \\
\hline
\end{tabular}

There were 182 respondents, and the average expected frequency in each cell of the Table was as small as 15. Additionally, since no sampling that considered the distribution of the teacher population of relevant regions took place, a detailed analysis based on Table 1 should be avoided. However, the following points can be understood as rough trends.

Most of the cluster 2 teachers are working within (1) city C, which is a prefectural capital; (2) the jurisdiction of the local education authority $\mathrm{M}$, adjacent to city $\mathrm{C}$ and covering the southern part of the prefecture; and (3) the jurisdiction of the local education authority $\mathrm{HK}$, adjacent to city $\mathrm{C}$ and covering the eastern part of the prefecture. On the other hand, it seems that many teachers who belong to cluster 1 are working within the jurisdiction of the local education authority $\mathrm{K}$, which was closer to the capital city than city $\mathrm{C}$ and contained a single core city. Clusters 
1 and 2 had almost the same number of participants who worked for local education authority T, which is in charge of the northwestern part of the prefecture, and local education authority HS, which is in charge of the northeastern part of the prefecture.

The distribution of teachers was analyzed about foreign students, who required the arrangement of relevant provisions in the same manner as pupils with a disability involved in inclusive education did.

The bottom line of Table 1 shows that proactive policies allowing pupils with disability to attend schools were implemented in the regions within the jurisdiction of local education authority $\mathrm{K}$, which had had many teachers belonging to cluster 1 . Moreover, there exist regions in which foreign pupils enrolled at a high $81 \%$ of the schools within the jurisdiction (Chiba Prefectural Board of Education and Certified NPO Class Room for Foreign Children, 2005).

For foreign pupils are enrolled in most of schools in the region, it is possible to conclude that cluster 1 teachers had an image of "various attributes in a group" in regard to the factor of diversity of attributes.

In contrast, foreign pupils enrolled in only $47 \%$ to $48 \%$ of the schools within the jurisdiction of local education authorities $\mathrm{M}$ and $\mathrm{HK}$, to which many teachers of cluster 2 belonged, excluding the city $\mathrm{C}$ education authority. The percentages were the lowest within the prefecture. The predominance of the image of inclusive education as relating to pupils with disabilities might have been influenced by the regional factors. For reference, the correlation coefficient between the rates of enrollment of foreign students for all local education authorities and the ratio of clusters 1 and cluster 2 teachers was computed. A significant correlation of $0.64(\mathrm{p}<.01)$ was obtained for the two factors (lower two lines in table 1).

In this survey, sufficient data to review regional factors was not collected. However, in the future, I would like to repeat reviews related to the perspective of special needs education, including provisions for foreign pupils.

\section{DISCUSSION AND CONCLUSION}

Inclusive education covers the "diversity of educational needs of pupils." In case only "children" are included, if the viewpoints for the educational needs of such children are lacking, so-called a "damping" state represented by "the worst form of integration" would take place. When the educational needs of children are included, children will consequently be included in the educational system. Phenomenologically speaking, those two situations may seem the same, however the differences between the two should be carefully understood.

Without this viewpoint, it will be difficult to respond to the problem that "inveigling pupils to mainstream schools" would be a tacit assumption upon the promotion of inclusive education (Ando, 2012). If inclusive education is promoted with an inaccurate image, a small-minded practice that simply focuses on the integration of opportunities in mainstream schools and classes will take place. As a result, a serious problem may occur; that is, although pupils with disability share opportunities with other children, the former will be excluded from educational opportunities. That kind of defective structures reaffirms the alarm that Kase (1997) sounded concerned the theory that "inclusion" was considered a monism.

There is no doubt that expanding the role and scope of responsibility of mainstream schools regarding inclusive education will be essential, although it is not correct to make this the basis of an argument for repudiating special schools. Shimizu (2010) pointed out that the inclusive education advocated by UNESCO means educational reform such that diversified children hindered via school education system can be included, and it does not necessarily mean dissolution by the inclusion of education of children with disability in mainstream education. The promotion of inclusive education has been strongly recognized in the U.K., yet the UK government has been continuously expanding the scope of responsibility of mainstream schools and has always simultaneously recognized the role and responsibility of special schools. We can regard the experience in the U.K. as a symbolic case (Sanagi, 2010).

The respondents in cluster 2 asserted an incorrect situation in which inclusive education meant the "repudiation of separated learning opportunities." Those contexts may become the soil in which a structure of exclusion of the entire 
school system would grow. It reflects the fact that many discussions about inclusive education based on the conflict of "integration or separation" are still taking place in Japan.

Vlachou (1997) pointed out that understanding the special needs of children tends to be tied up with the knowledge about disabilities that has been retained thus far and the restrictions of resources in schools. The same applies to the formation of images held by teachers concerning inclusive education. In Japan, this is reflected in the conventional educational system and practices.

It is essential that teachers' awareness and specific activities be obtained and formulated for further developing inclusive education, as pointed out by Shimizu (2012), through "teacher organization with a vision of inclusive education." For such a purpose, it is indispensable that teachers be able to retain an appropriate conceptual understanding of inclusive education, as well as accurate knowledge, by being given the opportunity to undertake various types of teacher training.

\section{AUTHOR NOTE}

By the concept of inclusive education, separated learning opportunities, such as special schools, are positioned as social resources. Such opportunities are conceptually consistent. However, there are some incorrect cases in which inclusive education is thought to entail the repudiation of separated opportunities. Thus, the level at which accurate knowledge about such point is retained was established. Moreover, the factor of "diversity of attributes" does not target only children with disability in inclusive education. However, this way of thinking has been established because, "special support education" has the same meaning as education for pupils with disabilities in Japan. Thus, such "special support education" may be narrowly understood in response to those influences.

\section{ACKNOWLEDGEMENTS}

This study has been supported by JSPS KAKENHI (Grant in Aid for Challenging Exploratory Research) grant number 26590255. (Japan). A part of this article was presented as "What Aspects Of Inclusive Education Are Emphasized By Teachers In Japan?" at International business \& education conferences, San Francisco 2014. (SF14366)

\section{CONFLICTS OF INTEREST}

The author has no conflict of interest directly relevant to the content of this article.

\section{AUTHOR BIOGRAPHY}

Dr. Tomomi Sanagi is a full professor of Faculty of Education, Chiba University, Japan, and also the leader of department of special needs education. His fields of research include developing a theory of special educational needs and inclusive education, and education system in U.K. and Denmark.

E-mail: sanagitomomi@gmail.com or sanagi@faculty.chiba-u.jp

\section{REFERENCES}

Ainscow, M. (1999). Understanding the development of inclusive schools. Falmer press. London.

Ando, F. (2012). Reform of systems for the disabled and inclusive education; Watabe,A. (eds.). The Way to the inclusive education in Japan, Sangaku Publishing. 68-77.

Benjamin, S. (2002). The micropolitics of inclusive education. -an ethnography-. Open university press. London.

Chiba Prefectural Board of Education and Certified NPO Class Room for Foreign Children (2005). Report on investigation and research on teaching of Japanese language for foreign students (Chiba Prefectural Board of Education).

Kase, S. (1997). Reconsideration of the concept of "Integration". SNE Journal, 2(1), 58-74.

Sanagi, T. (2010). Inclusive education in the U.K. Japanese Journal of Developmental Disability, 32(2), 152-158.

Sanagi, T. (2011). A design for experimental inclusive school. Bulletin of the faculty of education, Chiba University, 59, 1-6. Chiba, Japan.

Shimizu, S. (2010). Inclusive education. Mogi, T. (eds.) Encycropaedia in special needs education. Junposha. 40. Kyoto. 
Shimizu, S. (2012). A proposal for inclusive education. Creates KAMOGAWA.

Terzi, L.(eds.). Warnock, M. and Norwich, B. (2010). Special educational needs: a new look. Continuum. London.

Ueno, K. and Nakamura, K. (2011). Attitudes of teachers in mainstream schools towards inclusion education. Journal of health and sports science Juntendo, 3(2), 112-117.

UNESCO (1994). The Salamanca statement framework for action on special needs education. World conference on special needs education: access and quality.

Vlachou, A.D. (1997). Struggles for inclusive education. Open University Press. London.

Watanabe, A. (2012). The way to the inclusive education in Japan. Sangaku Publishing. iii. 